\title{
BMJ Open Seroprevalence of anti-SARS-CoV-2 antibodies after the first wave of the COVID-19 pandemic in a vulnerable population in France: a cross- sectional study
}

Adeline Beaumont (D) , ${ }^{1}$ Cécile Durand, ${ }^{1}$ Martine Ledrans, ${ }^{1}$ Valérie Schwoebel, ${ }^{1}$ Harold Noel, ${ }^{2}$ Yann Le Strat, ${ }^{3}$ Donatien Diulius, ${ }^{4}$ Léa Colombain, ${ }^{5}$ Marie Médus, ${ }^{5}$ Philippe Gueudet, ${ }^{6}$ Damien Mouly, ${ }^{1}$ Hugues Aumaître ${ }^{5}$

To cite: Beaumont $A$, Durand C, Ledrans M, et al. Seroprevalence of anti-SARSCoV-2 antibodies after the first wave of the COVID-19 pandemic in a vulnerable population in France: a crosssectional study. BMJ Open 2021;11:e053201. doi:10.1136/ bmjopen-2021-053201

- Prepublication history and additional supplemental material for this paper are available online. To view these files, please visit the journal online (http://dx.doi.org/10.1136/ bmjopen-2021-053201).

Received 12 May 2021 Accepted 26 October 2021

D) Check for updates

(c) Author(s) (or their employer(s)) 2022. Re-use permitted under CC BY-NC. No commercial re-use. See rights and permissions. Published by BMJ.

For numbered affiliations see end of article.

Correspondence to Dr Damien Mouly; damien.mouly@ santepubliquefrance.fr

\section{ABSTRACT}

Objectives We aimed to assess the level of prior SARS-

CoV-2 infection in socially deprived neighbourhoods after the first wave of the pandemic, and to identify factors associated with seropositivity.

Design A cross-sectional study.

Setting Three socially deprived neighbourhoods of the city of Perpignan, in the south of France, where large settled Roma communities live.

Participants People aged 6 years old or over, living in the study area. 700 people were included in the study using two-stage stratified sampling design.

Interventions The study included a questionnaire and SARS-CoV-2 antibody testing by the Roche Elecsys immunoassay between 29 June and 17 July 2020. Primary and secondary outcome measures SARSCoV-2 antibody seroprevalence was estimated from weighted data. Associated factors and reported symptoms were investigated using univariable and multivariable logistic regressions.

Results The seroprevalence of anti-SARS-CoV-2 antibodies was $35.4 \%(95 \% \mathrm{Cl} 30.2 \%$ to $41.0 \%)$. People aged 15-64 years old had increased odds of being seropositive than those aged 65 years or over. Obese people had higher odds of being seropositive (adjusted $\mathrm{OR}(\mathrm{aOR})=2.0,95 \% \mathrm{Cl} 1.1$ to 3.8$)$. The odds of being seropositive were higher in households with clinical COVID-19 cases (one case: $\mathrm{aOR}=2.5,95 \% \mathrm{Cl} 1.3$ to 5.0; several cases: $\mathrm{aOR}=6.9,95 \% \mathrm{Cl} 3.1$ to 15.2 ). In the neighbourhood with the highest measured seroprevalence, people living in a dwelling with one to two rooms had higher odds of being seropositive than those living in a four-room house (aOR=2.8, 95\% Cl 1.2 to 6.3$)$. Working during the lockdown was associated with lower odds of being seropositive ( $\mathrm{aOR}=0.2,95 \% \mathrm{Cl} 0.03$ to 1.0$)$. Conclusion Transmission of SARS-COV-2 in this vulnerable population was very high during the COVID-19 pandemic's first wave. Our results highlight the need to strengthen and adapt preventive measures taking into account all social determinants of health, especially housing conditions.

\section{STRENGTHS AND LIMITATIONS OF THIS STUDY}

$\Rightarrow$ We examined prevalence of SARS-CoV-2 antibodies and associated environmental and behavioural factors in a socially deprived population which is difficult to access.

$\Rightarrow$ A strong collaboration with mediators from the study population for the questionnaire design and the recruitment allowed a better participation of the population in the survey.

$\Rightarrow$ Collection of socioeconomic information was restricted to neighbourhood of residence and housing for reasons of acceptability by the participants.

$\Rightarrow$ Preventive behaviours and compliance with barrier measures were not studied in our analysis due to probable changes in behaviour during the lockdown.

$\Rightarrow$ Men and children were under-represented in the study sample.

\section{INTRODUCTION}

With the emergence of COVID-19 and the resulting pandemic, questions about social inequalities in health during the current crisis have been raised. ${ }^{1-4}$ Many health issues are involved, including inequalities in exposure to SARS-CoV-2, in the severity of the COVID-19 disease and in access to healthcare. $^{14-6}$ These concerns are all the more important given that these health inequalities are often cumulative, ${ }^{7}$ leading to a marked risk of increased social deprivation in vulnerable populations. ${ }^{358}$ Furthermore, lockdowns implemented in many countries have exacerbated pre-existing health inequalities. ${ }^{15910}$

During the ongoing epidemic, special attention has been given to some 10000 residents living in three of the poorest neighbourhoods (Haut-Vernet, Nouveau Logis and Saint-Jacques) in France. Located in the city of Perpignan (120000 inhabitants, Occitania 
region), the employment rate is very low in these neighbourhoods, with only $25 \%-30 \%$ of people aged $15-64$ years old being employed. ${ }^{11}$ Roma communities, calling themselves 'gitans' (gypsies), make up a large part of the population of the neighbourhoods where they have settled for several generations. They share commonalities in lifestyle and culture, with the roles of family and religion being especially important. In Europe, Roma communities have lower education levels and higher unemployment rates than the general public. They often have poorer living conditions and commonly face social exclusion. ${ }^{12}$ Furthermore, their health literacy level is low and they have their own perception of health and sickness. Sickness must have visible and tangible consequences for them to recognise it and act accordingly. ${ }^{13}$ Moreover, they have a poorer health status than that of the general population and face greater barriers to accessing healthcare. ${ }^{14-16}$

The first wave of the COVID-19 pandemic hit France at the beginning of 2020, leading to a national lockdown between 17 March and 11 May 2020. After the first positive case in Perpignan was detected using RT(reverse transcriptase)-PCR on 11 March 2020, the epidemic progressed rapidly in the city. On 20 March 2020, there were 47 confirmed cases in all the Pyrénées-Orientales 'department' (administrative area larger than a district but smaller than a region) (475000 inhabitants) where Perpignan is located. On the same day, the intensive care unit in Perpignan hospital reported 19 people hospitalised and 5 deaths. An analysis by the hospital's infectious and tropical diseases unit of all those diagnosed positive indicated that most of the patients were living in the three neighbourhoods described above. In order to control the situation, a curfew was implemented throughout the city beginning 21 March 2020 and accommodation facilities were offered to facilitate isolating positive cases and persons the latter had been in contact with. Outpatient medical centres were rapidly opened in the city's most affected neighbourhoods to provide care to clinical cases and to prevent the spread of the virus in less impacted neighbourhoods. Specific surveillance based on data from these centres was also set up to monitor the evolution of the epidemic. ${ }^{17}$ The mobilisation of various health and local actors ensured the swift dissemination of specific prevention information to the population throughout the first wave. On 1 May 2020, the epidemic had largely dissipated and 2 months after the lockdown, viral circulation was close to zero in Perpignan.

In this context, we conducted a seroprevalence study of anti-SARS-CoV-2 antibodies in Perpignan (SCoPe) in the three neighbourhoods described above to estimate the level of prior infection during the first epidemic wave. In addition, we analysed environmental and behavioural factors in order to identify factors associated with increased viral circulation.

\section{METHODS}

\section{Study design and participants}

Seroprevalence of COVID-19 in Perpignan (SCoPe) is a cross-sectional seroprevalence survey of a sample of

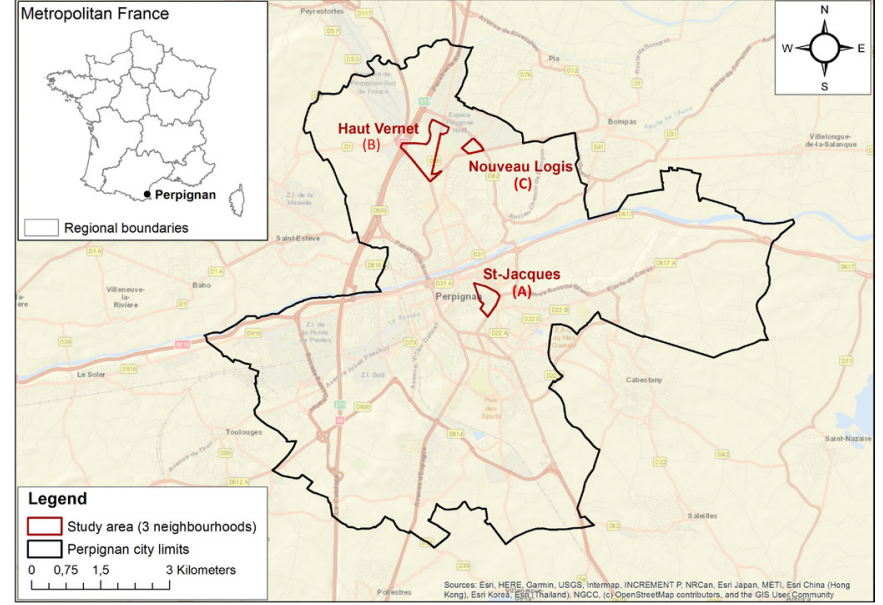

Figure 1 Map of the city of Perpignan and the three neighbourhoods studied.

the population living in three neighbourhoods (SaintJacques (neighbourhood A), Haut-Vernet (neighbourhood B) and Nouveau Logis (neighbourhood C)) in the city of Perpignan (figure 1). It was conducted between 29 June and 17 July 2020.

The limits of neighbourhoods A and B were demarcated using data from the French National Institute of Statistics and Economic Studies, and neighbourhood C from city data (priority neighbourhood for social actions).

As sampling frames were unavailable for inhabitants or dwellings, we chose a two-stage random sampling process (households, inhabitants) stratified by neighbourhood. The field investigators criss-crossed each neighbourhood to select households for potential participation by systematic sampling from a predefined route and sampling interval generated by the research team. In a second step, we randomly selected at least one person in each household using the next-birthday method. ${ }^{18}$ The number of selected persons was predetermined according to the number of eligible persons in the household: one if one to two, two if three to four persons, three if five to six persons, and four if seven or over persons (see online supplemental materials-Survey procedure and logistics). Recruitment was carried out by teams of field investigators comprising members of the Roma community and local social workers.

Individuals were eligible if they were 6 years old or over, had resided in the study area between 1 January 2020 and the survey date, were physically able to move to one of the study's five purpose-built survey centres and were able to answer the survey questionnaire.

Participants were referred to the neighbourhood's survey centre, where physicians used a standardised questionnaire in French-specifically designed for SCoPe- to collect information on the following: sociodemographic characteristics, medical conditions associated with the risk of severe COVID-19, ${ }^{19}$ occurrence of symptoms suggestive of COVID-19 and healthcare-seeking behaviour since 24 February 2020, characteristics of both the household and the housing the participants lived 
in during the first lockdown, knowledge of COVID-19 prevention measures and behaviours during the first lockdown (see online supplemental materials-Questionnaire). Members of the Roma community were not identified in the questionnaire because of the prohibition of collection of ethnic statistics in France. BMI (Body mass index) was calculated by measuring height and weight and was categorised according to standard cut-off points for obesity $\left(\right.$ BMI $\left.\geq 30 \mathrm{~kg} / \mathrm{m}^{2}\right) .{ }^{19}$ Other quantitative variables (age, number of rooms, number of clinical COVID-19 cases) were categorised from the results of the univariable analysis. A blood sample was collected by venepuncture for each participant: $3.5 \mathrm{~mL}$ for those aged 18 years old and over, and $600 \mu \mathrm{l}$ for those aged $6-17$ years old.

\section{Laboratory analysis}

Samples were stored locally for a maximum of 12 hours at less than $5^{\circ}$ before being transferred to the laboratory at Perpignan Hospital.

Serological tests were performed using EIecsys AntiSARS-CoV-2, ${ }^{20}$ an immunoassay for in vitro qualitative detection of IgM and IgG antibodies against the SARS$\mathrm{CoV}-2$ spike protein in serum. Its sensitivity is $99.5 \%$ (95\% CI $97 \%$ to $100 \%$ ) at $\geq 14$ days after PCR confirmation. Overall specificity is $99.8 \%$ (95\% CI $99.69 \%$ to $99.88 \%$ ). ${ }^{20}$

\section{Statistical analysis}

SCoPe's estimations take into account the sampling design components (stages, sampling weights, stratification). Data were weighted by the inverse of the probability of selection (sampling weight) and adjusted for the age and sex in each neighbourhood using data of selected persons who declined to participate in the study, and from post-stratification using data from the most recent population census (2017).

A person was defined seropositive if anti-SARS-CoV-2 antibodies (IgM or IgG) were detected by the immunoassay. Seroprevalence (ie, the proportion of seropositive individuals) was estimated with a $95 \%$ CI. Association of seroprevalence with the neighbourhood, other individual characteristics and reported symptoms were preliminarily tested by univariable analysis with Rao-Scott $\chi 2$ test. Factors associated with seropositivity were then analysed using a multivariable logistic regression taking into account the sampling design. We reported ORs (unadjusted and adjusted) and adjusted Wald $\mathrm{F}$ test for significance for each variable. Behaviours during the lockdown were excluded from the multivariable analysis, except for leaving home to go to work. Age, sex and neighbourhood were always retained into the multivariable model. For the other variables, a forward selection procedure was applied and variables with a $p$ value of $<0.1$ were retained. Interactions were tested. A $p$ value of $<0.05$ was considered statistically significant. Data were analysed using Stata V.14.2 software (StataCorp, College Station, Texas, USA).
Neighbourhoods: Saint Jacques (A),

Haut-Vernet (B), Nouveau Logis (C)

1117 households selected and approached

Recruitment

$\rightarrow 102$ excluded:

96 uninhabited dwellings

6 ineligible households

$\rightarrow 162$ no contact

853 eligible households with contact

$\rightarrow 225$ household refusals

628 households intending to participate

2294 individuals in households

$\rightarrow 193$ ineligible individuals

2101 eligible individuals

1248 individuals selected at random

$\rightarrow 79$ individual refusals

1169 individuals intending to participate

\begin{tabular}{l|l} 
Phase II & $\rightarrow 464$ did not come to the survey
\end{tabular}

Screening

centres

$\rightarrow 5$ no serology

1 uninterpretable

700 individuals included

422 households included

Figure 2 Flow chart of participants.

\section{Patient and public involvement}

The questionnaire was designed in collaboration with local mediators in order to ensure that it would be acceptable to the study population and that they could understand it. Then, they implemented the selection phase of participants and provided them information about the survey. Participants received their individual results of antibodies anti-SARS-CoV-2 analysis in the week following the samples.

\section{RESULTS}

Of the total 1117 households initially selected for the study, 853 were visited and invited to participate (figure 2). Of the latter, 628 (73.6\%) households with 2101 eligible individuals agreed to partake in the random participant selection stage. The rate of those agreeing to partake in this stage varied between all three neighbourhoods: $78.7 \%$ in neighbourhood A, 48.7\% in neighbourhood B and $98.9 \%$ in neighbourhood C. Among the 1248 individuals subsequently selected at random from the 2101 who were eligible, $700(56.1 \%)$ went to the survey centres and were included in the analysis (ie, study population): 312 from neighbourhood A (48.4\%), 173 from neighbourhood B $(70.0 \%)$ and 215 from neighbourhood C $(60.4 \%)$.

A total of 287 men (41.0\%) and 413 women (59.0\%) participated in the study. Among all participants, 117 
(16.7\%) were aged between 6 and 19 years, 468 (66.9\%) between 20 and 64 years, and $115(16.4 \%)$ were aged 65 years or over. After weighting data, men and children were under-represented. Therefore, post-stratification adjustment was applied.

\section{Study population}

After post-stratification, women accounted for $50.4 \%$ of the study population. One-third $(34.3 \%)$ of the population was aged between 6 and 19 years old, $53.7 \%$ between 20 and 64 years old, while $12.0 \%$ were 65 years old or over.

Obesity prevalence was $40.7 \%$ (95\% CI $35.8 \%$ to $45.8 \%$ ): $43.5 \%$ (95\% CI $38.9 \%$ to $48.3 \%$ ) in adults (BMI $\geq 30 \mathrm{~kg} / \mathrm{m}^{2}$ ) and $34.0 \%$ (95\% CI $22.2 \%$ to $48.2 \%$ ) in those aged 6-17 years old (International Obesity Task Force (IOTF); BMI $\geq$ IOTF-30 cut-off points). Fifteen per cent (95\% CI $13.0 \%$ to $17.3 \%)$ of the study population reported having hypertension, $7.0 \%$ (95\% CI $5.5 \%$ to $8.8 \%$ ) heart disease, $9.4 \%$ (95\% CI $7.7 \%$ to $11.4 \%$ ) were being treated for diabetes, $5.5 \%$ (95\% CI $4.0 \%$ to $7.7 \%$ ) had asthma, while $4.9 \%$ (95\% CI $3.7 \%$ to $6.6 \%$ ) had (an) other chronic respiratory disease(s).

The majority of those in neighbourhood A were living in an apartment $(71.5 \%, 95 \%$ CI $64.6 \%$ to $77.6 \%)$, while the majority of people in neighbourhoods $\mathrm{B}$ and $\mathrm{C}$ were living in a house $(73.9 \%, 95 \%$ CI $62.8 \%$ to $82.6 \%$, and $83.9 \%, 95 \%$ CI $79.0 \%$ to $87.8 \%$, respectively). The number of people per room (except the living room) in each home was greater than one for $75.3 \%$ (95\% CI $69.9 \%$ to $80.1 \%$ ) of people living in neighbourhood A, for $55.5 \%$ (95\% CI $46.9 \%$ to $63.7 \%$ ) in neighbourhood $\mathrm{B}$ and for $80.5 \%$ (95\% CI $75.8 \%$ to $84.6 \%$ ) in neighbourhood C. Detailed characteristics by neighbourhood are described in online supplemental table 1.

\section{Seroprevalence}

Overall seroprevalence was estimated at $35.4 \%$ (95\% CI $30.2 \%$ to $41.0 \%$ ) for all three neighbourhoods. It was significantly higher in neighbourhood A $(46.7 \%, 95 \%$ CI $39.0 \%$ to $54.7 \%$ ) than in neighbourhoods $\mathrm{B}$ and $\mathrm{C}$ $(13.9 \%, 95 \%$ CI $8.2 \%$ to $22.6 \%$, and $17.1 \%, 95 \%$ CI $13.0 \%$ to $22.2 \%$, respectively).

\section{Symptoms during the study period}

Among seropositive people, $21.7 \%$ (95\% CI $14.1 \%$ to $31.8 \%)$ reported no symptoms suggestive of COVID-19 during the study period (from 24 February 2020 to the survey date). One in seven $(14.6 \%, 95 \%$ CI $9.5 \%$ to $21.9 \%$ ) of those who reported no symptoms were tested seropositive. Seropositive people mostly reported unusual fatigue $(58.9 \%, 95 \%$ CI $48.9 \%$ to $68.2 \%)$, a headache $(51.7 \%, 95 \%$ CI $42.4 \%$ to $60.9 \%)$, ageusia/anosmia $(49.8 \%, 95 \%$ CI $40.2 \%$ to $59.4 \%)$, a fever or a feeling of having a fever $(49.1 \%, 95 \%$ CI $40.6 \%$ to $57.6 \%)$, a cough $(46.4 \%, 95 \%$ CI $37.5 \%$ to $55.5 \%)$ and myalgia $(45.7 \%$, $95 \%$ CI $37.4 \%$ to $54.3 \%$ ).

There was a significant positive association between seropositivity and symptoms $(\mathrm{OR}=8.1,95 \%$ CI 4.5 to 14.6 ,

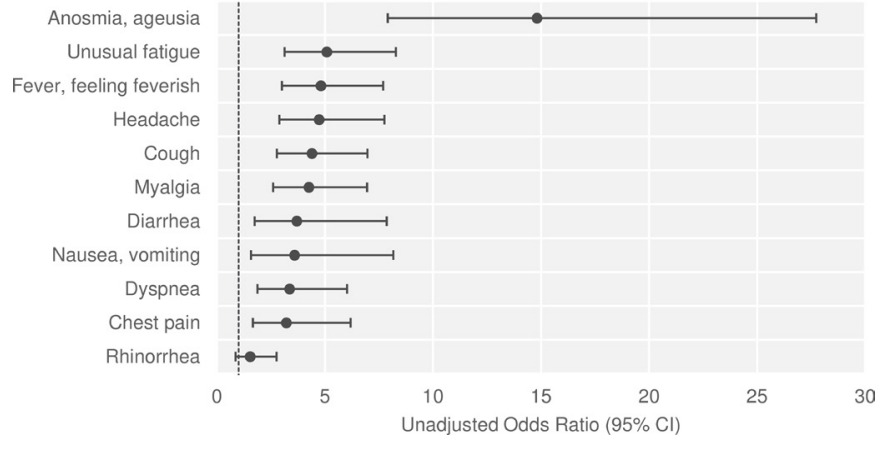

Figure 3 Association between seropositivity and reporting symptoms. Analysis performed on all sampled individuals $(n=700)$ using simple logistic regressions.

$\mathrm{p}<0.001)$. Ageusia/anosmia were the symptoms most strongly associated with seropositivity $(\mathrm{OR}=14.8,95 \% \mathrm{CI}$ 7.9 to $27.7, \mathrm{p}<0.001$ ), with positive and negative predictive values of $81.3 \%$ (95\% CI $71.5 \%$ to $88.3 \%$ ) and $77.3 \%$ (95\% CI $71.4 \%$ to $82.4 \%$ ), respectively. All other symptoms were also significantly associated with seropositivity, except for rhinorrhoea (figure 3).

\section{Healthcare-seeking behaviours during the study period}

During the study period, $15.8 \%$ (95\% CI $11.3 \%$ to $21.6 \%$ ) of symptomatic people consulted a COVID-19 centre when symptoms occurred and 9.6\% (95\% CI 6.6\% to $13.6 \%$ ) had an RT-PCR test (positive PCR=29.0\%). Specifically, $41.8 \%$ of seropositive participants tested with RT-PCR had a positive result.

Among seropositive participants, $7.9 \%$ (95\% CI 4.6\% to $13.2 \%$ ) had been hospitalised during the study period, almost all having had medical conditions associated with severe COVID-19 (89.3\%).

\section{Factors associated with seropositivity}

In the univariable analysis (table 1), people aged 65 years or over had lower odds of being seropositive $(p<0.001)$. No significant difference was observed between males and females regarding the odds of being seropositive. Obese people had higher odds of being seropositive $(\mathrm{OR}=2.0$, $95 \%$ CI 1.3 to 3.2). The presence of one (OR=3.0, 95\% CI 1.8 to 5.2 ) or more ( $\mathrm{OR}=7.8,95 \% \mathrm{CI} 4.0$ to 15.2 ) clinical COVID-19 cases in the household was associated with increased odds of being seropositive. People living in a dwelling with three or fewer rooms (one to two rooms: $\mathrm{OR}=2.1,95 \%$ CI 1.2 to 3.8 ; three rooms: $\mathrm{OR}=2.2,95 \% \mathrm{CI}$ 1.3 to 3.9 ) had higher odds of being seropositive. The proportion of seropositive people increased with the number of people per room in the dwelling $(p=0.001)$. People who worked during the lockdown had reduced odds of being seropositive ( $\mathrm{OR}=0.1,95 \%$ CI 0.02 to 0.5 ). Furthermore, people who reported leaving their home once a week or less for walks during the lockdown had lower odds of being seropositive than people who went out every day or almost every day $(\mathrm{OR}=0.2,95 \% \mathrm{CI} 0.1$ to $0.7)$. 
Table 1 Factors associated with SARS-CoV-2 seropositivity: univariable analysis

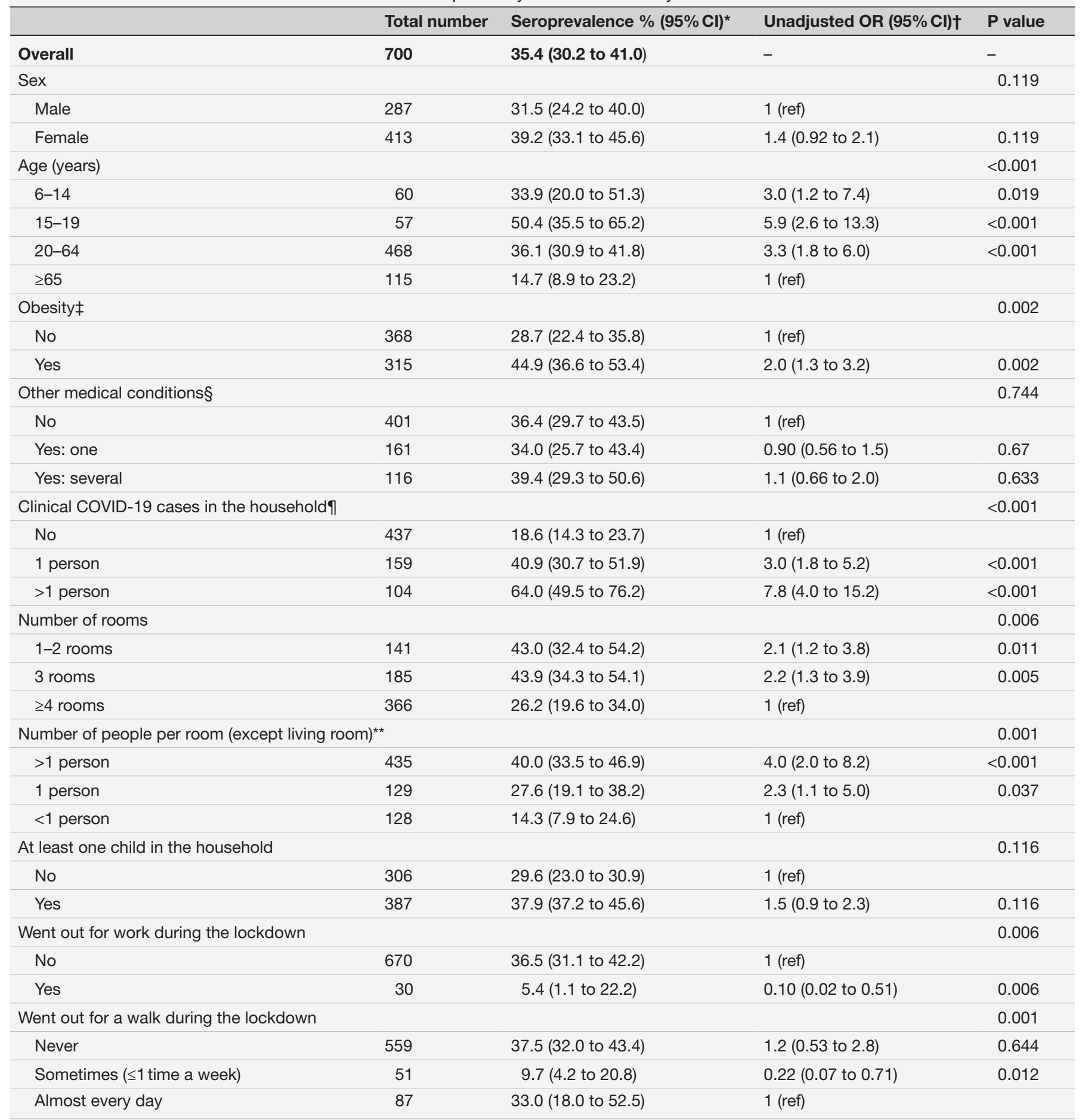

*Seroprevalence estimated from weighted data.

†Unadjusted OR with corresponding $95 \% \mathrm{Cls}$ and $\mathrm{p}$ values from univariable logistic regressions.

fFor those aged 18 years or older: BMI $\geq 30 \mathrm{~kg} / \mathrm{m}^{2}$; for those aged 6-17 years: BMI (body mass index) $\geq 1 \mathrm{OTF}$ ((International Obesity Task Force) -30 cut-off points.

§Other medical conditions including: asthma, other respiratory diseases, hypertension, heart disease, treated diabetes, treated cancer (excluding hormone therapy), HIV and immunodeficiency, chronic liver disease, chronic kidney disease, neuromuscular diseases.

IIClinical COVID-19 cases in the household: number of people, except the respondent, with clinical signs of COVID-19 (cough, fever), a positive RTPCR test or who consulted for suspected COVID-19 since 24 February 2020.

**Living rooms were excluded, except for single people, in order to measure the potential for isolation in the dwellings. Indicator calculated: ([number of people]/number of rooms-1]).

IOTF, International Obesity Task Force. 
Table 2 Factors associated with SARS-CoV-2

seropositivity: multivariable analysis

\begin{tabular}{|c|c|c|}
\hline & Adjusted OR $(95 \% \mathrm{Cl})^{*}$ & $P$ value \\
\hline \multicolumn{2}{|l|}{ Sex } & 0.034 \\
\hline Male & 1 (ref) & \\
\hline Female & 1.8 (1.0 to 3.3$)$ & 0.034 \\
\hline \multicolumn{2}{|l|}{ Age (years) } & $<0.001$ \\
\hline $6-14$ & 1.8 (0.53 to 6.1$)$ & 0.344 \\
\hline $15-19$ & 9.1 (2.8 to 29.8$)$ & $<0.001$ \\
\hline $20-64$ & $4.5(2.0$ to 10.1$)$ & $<0.001$ \\
\hline$\geq 65$ & 1 (ref) & \\
\hline \multicolumn{2}{|l|}{ Obesity† } & 0.024 \\
\hline No & 1 (ref) & \\
\hline Yes & $2.0(1.1$ to 3.8$)$ & 0.024 \\
\hline \multicolumn{2}{|c|}{ Other medical conditions $\ddagger$} & 0.004 \\
\hline No & 1 (ref) & \\
\hline Yes: one & 1.1 (0.57 to 2.0$)$ & 0.863 \\
\hline Yes: several & $3.2(1.6$ to 6.3$)$ & 0.001 \\
\hline \multicolumn{2}{|c|}{ Clinical COVID-19 cases in the household§ } & $<0.001$ \\
\hline No & 1 (ref) & \\
\hline 1 person & 2.5 (1.3 to 5.0$)$ & 0.007 \\
\hline$>1$ person & 6.9 (3.1 to 15.2$)$ & $<0.001$ \\
\hline \multicolumn{2}{|c|}{ Went out for work during the lockdown } & 0.048 \\
\hline No & 1 (ref) & \\
\hline Yes & $0.18(0.03$ to 1.0$)$ & 0.048 \\
\hline \multicolumn{2}{|c|}{ Number of rooms by neighbourhood } & 0.007 \\
\hline \multicolumn{3}{|c|}{ Neighbourhood A } \\
\hline $1-2$ & 2.8 (1.2 to 6.3$)$ & 0.016 \\
\hline 3 & $2.2(1.0$ to 5.0$)$ & 0.064 \\
\hline$\geq 4$ & 1 (ref) & \\
\hline \multicolumn{3}{|c|}{ Neighbourhood B } \\
\hline $1-2$ & $1.5(0.3$ to 6.4$)$ & 0.594 \\
\hline 3 & 0.23 (0.04 to 1.2$)$ & 0.075 \\
\hline$\geq 4$ & 1 (ref) & \\
\hline \multicolumn{3}{|c|}{ Neighbourhood C } \\
\hline $1-2$ & $0.58(0.22$ to 1.5$)$ & 0.262 \\
\hline 3 & $2.3(0.91$ to 5.9$)$ & 0.078 \\
\hline$\geq 4$ & 1 (ref) & \\
\hline
\end{tabular}

${ }^{*}$ Adjusted OR with corresponding 95\% Cls and $p$ values from multivariable logistic regression. Analysis performed on 655 of 700 sampled individuals.

†For those aged 18 years or older: $\mathrm{BMI} \geq 30 \mathrm{~kg} / \mathrm{m}^{2}$; for those aged 6-17 years: BMI (body mass index) $\geq I O T F$ (International Obesity Task Force) -30 cut-off points.

fOther medical conditions including: asthma, other respiratory diseases, hypertension, heart disease, treated diabetes, treated cancer (excluding hormone therapy), HIV and immunodeficiency, chronic liver disease, chronic kidney disease, neuromuscular diseases. $\S$ Clinical COVID-19 cases in the household: number of people, except the respondent, with clinical signs of COVID-19 (cough, fever), a positive RT-PCR test or who were consulted for suspected COVID-19 since 24 February 2020.

q|Model includes an interaction term: number of rooms $\times$ neighbourhood.

IOTF, International Obesity Task Force.
In the multivariable analysis (table 2), the association between seropositivity and the presence of clinical cases in the household remained strong after adjusting for other factors (one person: adjusted $\mathrm{OR}(\mathrm{aOR})=2.5,95 \% \mathrm{CI} 1.3$ to 5.0 ; $\geq 2$ persons: aOR $=6.9,95 \%$ CI 3.1 to 15.2 ). People aged $15-19$ years (aOR 9.1, 95\% CI 2.8 to 29.8 ) and 20-64 years $(\mathrm{aOR}=4.5,95 \% \mathrm{CI} 2.0$ to 10.1$)$ had higher odds of being seropositive than those aged 65 years or over. Females had increased odds of being seropositive than males $(\mathrm{aOR}=1.8,95 \% \mathrm{CI} 1.0$ to 3.3$)$. Seropositivity was significantly associated with obesity $(\mathrm{aOR}=2.0,95 \% \mathrm{CI} 1.1$ to 3.8$)$ and other medical conditions $(\mathrm{aOR}=3.2,95 \% \mathrm{CI}$ 1.6 to 6.3 ). There was a significant interaction between the neighbourhood and the number of rooms in the dwelling $(p=0.004)$. People living in a one-room or tworoom dwelling in neighbourhood $\mathrm{A}$ had higher odds of being seropositive than those living in a dwelling with four or more rooms $(\mathrm{aOR}=2.8,95 \%$ CI 1.2 to 6.3$)$. Working during lockdown remained associated with decreased odds of being seropositive ( $\mathrm{aOR}=0.2,95 \%$ CI 0.03 to 1.0 ).

\section{DISCUSSION}

Our findings from the SCoPe seroprevalence study in three socially deprived neighbourhoods with a large settled Roma community in Perpignan indicate that more than one in three $(35.4 \%)$ people developed antibodies against SARS-CoV-2 during the first months of the COVID-19 epidemic. In comparison, estimates for the general population in May 2020 indicated an antibody prevalence of $1.9 \%$ in the Occitania region (where Perpignan is situated) and less than 5\% in France and Spain (Perpignan is located very close to the Spanish border). ${ }^{2122}$

Although the proportion of asymptomatic SARS-CoV-2 infections varies greatly from one study to another, the proportion we found $(21.7 \%$ ) was comparable with the results of two meta-analyses $(20 \%, 95 \% \text { CI } 17 \% \text { to } 25 \%)^{23}$ $(17 \%, 95 \%$ CI $14 \%$ to $20 \%) .{ }^{24}$ The specificity of ageusia/ anosmia symptoms was found to be very high, although this could not be confirmed by a temporal analysis which was not possible in this cross-sectional study. Such a high specificity has already been observed in numerous other studies. ${ }^{25}$ It would be useful for developing a strategy for early diagnosis of COVID-19 and self-isolation.

Lower seroprevalence was reported among study participants aged 65 years and over. This may partially be explained by a result from a qualitative study simultaneously conducted with SCoPe which found that this older population went outdoors less frequently and had fewer social contacts during the first wave of the epidemic thanks to the very protective stance adopted by the local community. ${ }^{26}$ In addition, females were more likely to be seropositive in the multivariable analysis. The associations between seropositivity and age and between seropositivity and sex respectively differ between studies, although several have found a lower seroprevalence among older people, particularly in France. ${ }^{21} 2627$ The fact that few 
seroprevalence studies have been conducted to date in a similar context (high level of infection, socially deprived neighbourhood) could explain these differences.

Our results showed that obese people had higher seroprevalence of SARS-CoV-2 antibodies independently from other factors. This is consistent with the findings of a meta-analysis of 20 published studies on the subject $(\mathrm{OR}=1.46,95 \%$ CI 1.30 to 1.65$) .{ }^{28}$ Obesity has been associated with low socioeconomic status. ${ }^{29}$ The association we found between obesity and seropositivity may be explained by potential confounders linked to unfavourable socioeconomic conditions. SCoPe did not comprehensively measure these conditions for reasons of study acceptability. Metabolic and immune dysfunction and inflammatory mechanisms may be implicated in the clinical aggravation of COVID-19 in obese people. ${ }^{30-32}$ These mechanisms might also be involved in increasing the risk of infection, although this association is less well established. Prolonged viral shedding in obese people, something already seen for influenza, ${ }^{33}$ may also occur for SARS-CoV-2 and could play a role in the spread of the virus in families where obesity is prevalent.

Our study also confirms findings elsewhere that the risk of transmission is greater when a clinical case is present in the same household. ${ }^{21}{ }^{22}$ Working outside the home during the first lockdown was associated with a lower risk of seropositivity. This result may reflect a higher socioeconomic status of people who worked. Other hypotheses (compliance with barriers measures, healthy worker effect, etc) could be formulated to explain this result, but cannot be further explored without additional data.

In our study, seroprevalence was higher for people living in crowded housing, and after adjusting for other factors, small dwelling size was a significant associated factor, but only in neighbourhood A. This result was also found in other French studies. ${ }^{21}{ }^{34}$ In addition, living conditions-not analysed in our study-may also explain the higher seroprevalence in this particular neighbourhood. Population density, a factor associated with higher seroprevalence elsewhere, ${ }^{21} 22$ was higher in neighbourhood A than in both other neighbourhoods. The majority of accommodation in neighbourhood A comprises flats, and almost one-quarter of all dwellings are less than $40 \mathrm{~m}^{2} .^{35}$ Insalubrity was also very present in neighbourhood A, which is one of the priority areas in an ongoing national urban renewal programme. ${ }^{36}$ Accordingly, ventilation problems, lack of outdoor space and overcrowding may explain the higher risk of contamination. In general, the community-based lifestyle of the Roma population may also have increased the risk of contact with a clinical COVID-19 case.

Overall, we achieved a $56 \%$ participation rate in this difficult-to-reach population thanks to local mediators and contacts, whose collaboration was essential. Furthermore, despite the unavailability of sampling frames, the study was designed and implemented very quickly after the first wave ended, thanks to careful training and supervision of the interviewers throughout the field survey.
This speed of implementation was necessary given the uncertainties surrounding the duration of SARS-CoV-2 IgG antibodies after infection.

Our study has several limitations. First, it was conducted 4 months after the first wave ended, leading to possible recall bias in the reporting of symptoms. The assessment of behaviours during lockdown was very complex because of the fact that their evolution was not measured during the course of the first wave. It is important to underline that a qualitative study observed a shift in the three neighbourhoods' awareness of the dangers of COVID-19 following the first deaths, particularly that of a young woman. ${ }^{26}$ The same study observed a substantial improvement in compliance with prevention measures during the lockdown. This is why the association between these behaviours and seropositivity (except for going out to work) was not studied in our analysis. Second, the systematic sampling method used to select households made it difficult to estimate the total number of individuals to approach. Third, although we consider the participation rate to be acceptable in this field study setting, it was suboptimal and with lower participation of children and men. However, we accounted for this bias by using post-stratification. We also had difficulties reaching some of the selected households, despite flyers being placed in letterboxes and several visits. Furthermore, selection bias may have occurred. More specifically, people with a history of COVID-19-type symptoms may have been more willing to participate in the study than people with no such history. It is also possible that people who had been tested positive before the study were less willing to participate. Incomplete data on reasons for non-response prevented us from further exploring this issue. Finally, a more in-depth analysis at the household level would be relevant in view of intrahousehold infections. However, our study design did not allow for this type of analysis.

The high estimated seroprevalence after the first wave of SARS-CoV-2 infection in the three socially deprived neighbourhoods in the present study confirms the very high vulnerability to COVID-19 of populations living in socially deprived conditions, and underlines the need for more sophisticated surveillance and specific disease prevention measures. ${ }^{37}$ Additional observations using a sociological approach should provide an accurate assessment of the ability of this population to improve their level of health literacy and to assimilate protective measures. Although underlying mechanisms remain unclear, our results support previous findings that obese individuals are at higher risk of SARS-CoV-2 infection, and confirm the importance of conducting preventive interventions in this population. This is especially relevant as future vaccines might be less effective for these people. ${ }^{30} 33$ All vaccination strategies should be designed to ensure that they are acceptable to this vulnerable population. ${ }^{38}$

The long-term protection of vulnerable populations such as that in the present study who are particularly exposed to health and environmental crises must be improved by strengthening specific prevention and health 
promotion programmes and reducing social inequalities in health. ${ }^{39}$ In this context, policies against substandard housing have a key role in improving living conditions. Finally, health strategies can only be successful by ensuring long-term partnerships with organisations and stakeholders capable of rapid mobilisation in the event of a crisis.

\section{Author affiliations}

${ }^{1}$ Santé publique France, Direction des régions, Occitanie, Toulouse, France

${ }^{2}$ Santé publique France, Direction des maladies infectieuses, Saint-Maurice, France

${ }^{3}$ Santé publique France, Direction appui traitements et analyses des données,

Saint-Maurice, France

${ }^{4}$ Agence régionale de Santé Occitanie, délégation départementale Pyrénées Orientales, Perpignan, France

${ }^{5}$ Infectious and Tropical Diseases Department, Perpignan Hospital Center, Perpignan, France

${ }^{6}$ Laboratory of Biochemistry and Biology, Perpignan Hospital Center, Perpignan, France

Acknowledgements We would like to thank the field-based interviewers, the nursing staff (Centre Hospitalier de Perpignan, Perpignan, France) and Anne Guinard (Santé publique France, the National Public Health Agency, Saint-Maurice, France) who participated in the recruitment phase of the study. We thank Clothilde Hachin (Santé publique France, Saint-Maurice, France) for her support on the study protocol, Séverine Bailleul (Santé publique France, Saint-Maurice, France) for her help during preparation of the study, Gabrielle Jones (Santé publique France, Saint-Maurice, France) for her technical support, and Jude Sweeney (translator/ copyeditor) for the English revision.

Contributors $A B$ was responsible for data analysis, data interpretation, manuscript writing and submission, and participated in study design, protocol writing, data collection (coordination) and training of field investigators. CD was responsible for study design and online questionnaire, and participated in protocol writing, data collection (coordination), data analysis, and data manuscript writing. ML was responsible for protocol writing and participated in study design, data collection (coordination), training of field investigators, data interpretation and manuscript writing. VS participated in data collection (coordination), training of field investigators, data interpretation and manuscript writing. HN and YLS participated in data analysis and manuscript revision. DD participated in data collection (coordination) and manuscript revision. LC and MM participated in data collection (serology) and manuscript revision. PG was responsible for serological analysis. DM was responsible for organising data collection and ethics committee approval, and participated in study design, protocol writing, data collection, data interpretation, manuscript writing and submission, manuscript guarantor. HA initiated the study, was responsible for organising data collection, and participated in ethics committee approval, data interpretation and manuscript writing.

Funding This study was done by Perpignan Hospital and Santé publique France, the National Public Health Agency, as part of their missions from the routine institutional funds. Both structures are funded by the French Ministry of Health.

Map disclaimer The inclusion of any map (including the depiction of any boundaries therein), or of any geographic or locational reference, does not imply the expression of any opinion whatsoever on the part of BMJ concerning the legal status of any country, territory, jurisdiction or area or of its authorities. Any such expression remains solely that of the relevant source and is not endorsed by BMJ. Maps are provided without any warranty of any kind, either express or implied.

Competing interests None declared.

Patient consent for publication Not required.

Ethics approval The study protocol was approved by a French ethics committee (Comité de Protection des Personnes Sud Est II, Lyon, 2020-A01828-31). All participants were informed about the processing of personal data and of their rights. All gave their prior oral consent to participate. For those under 18 years of age, a parent or legal guardian provided consent.

Provenance and peer review Not commissioned; externally peer reviewed.

Data availability statement Data are available upon reasonable request. Anonymised data are available for researchers from the corresponding author, Damien Mouly, on reasonable request.
Supplemental material This content has been supplied by the author(s). It has not been vetted by BMJ Publishing Group Limited (BMJ) and may not have been peer-reviewed. Any opinions or recommendations discussed are solely those of the author(s) and are not endorsed by BMJ. BMJ disclaims all liability and responsibility arising from any reliance placed on the content. Where the content includes any translated material, BMJ does not warrant the accuracy and reliability of the translations (including but not limited to local regulations, clinical guidelines, terminology, drug names and drug dosages), and is not responsible for any error and/or omissions arising from translation and adaptation or otherwise.

Open access This is an open access article distributed in accordance with the Creative Commons Attribution Non Commercial (CC BY-NC 4.0) license, which permits others to distribute, remix, adapt, build upon this work non-commercially, and license their derivative works on different terms, provided the original work is properly cited, appropriate credit is given, any changes made indicated, and the use is non-commercial. See: http://creativecommons.org/licenses/by-nc/4.0/.

\section{ORCID iD}

Adeline Beaumont http://orcid.org/0000-0001-7466-2160

\section{REFERENCES}

1 Bambra C, Riordan R, Ford J, et al. The COVID-19 pandemic and health inequalities. J Epidemiol Community Health 2020;74:964-8.

2 Chung RY-N, Dong D, Li MM, . Socioeconomic gradient in health and the covid-19 outbreak. BMJ 2020;369:m1329.

3 Shadmi E, Chen Y, Dourado I, et al. Health equity and COVID-19: global perspectives. Int J Equity Health 2020;19:104.

4 Wang Z, Tang K. Combating COVID-19: health equity matters. Nat Med 2020;26:458.

5 DREES. Les inégalités sociales face l'épidémie de Covid-19. Etat des lieux et perspectives [in French]. Les dossiers de la DREES 2020;40.

6 Okonkwo NE, Aguwa UT, Jang M, et al. COVID-19 and the US response: accelerating health inequities. BMJ Evid Based Med 2020. doi:10.1136/bmjebm-2020-111426. [Epub ahead of print: 03 Jun 2020].

7 Bajos N, Jusot F, Pailhé A, et al. When lockdown policies amplify social inequalities in COVID-19 infections: evidence from a crosssectional population-based survey in France. BMC Public Health 2021;21:705.

8 Abedi V, Olulana O, Avula V, et al. Racial, economic, and health inequality and COVID-19 infection in the United States. J Racial Ethn Health Disparities 2021;8:732-42.

9 Wright L, Steptoe A, Fancourt D. Are we all in this together? Longitudinal assessment of cumulative adversities by socioeconomic position in the first 3 weeks of lockdown in the UK. $J$ Epidemiol Community Health 2020;74:683-8.

10 González-Rábago Y, Cabezas-Rodríguez A, Martín U. Social inequalities in health determinants in Spanish children during the COVID-19 Lockdown. Int J Environ Res Public Health 2021;18:4087.

11 Bordet C, Bourniquel C, Flachère M. Quartiers prioritaires de la politique de la ville en Occitanie : les multiples visages de la pauvreté. Insee Dossier Occitanie: Insee Occitanie, 2018: 151-5.

12 Parekh N, Rose T. Health inequalities of the Roma in Europe: a literature review. Cent Eur J Public Health 2011;19:139-42.

13 Ramos-Morcillo AJ, Leal-Costa C, Hueso-Montoro C, et al. Concept of health and sickness of the Spanish gypsy population: a qualitative approach. Int J Environ Res Public Health 2019;16:4492.

14 Hajioff S, McKee M. The health of the Roma people: a review of the published literature. J Epidemiol Community Health 2000;54:864-9.

15 Cook B, Wayne GF, Valentine A, et al. Revisiting the evidence on health and health care disparities among the Roma: a systematic review 2003-2012. Int J Public Health 2013;58:885-911.

16 McFadden A, Siebelt L, Gavine A, et al. Gypsy, Roma and traveller access to and engagement with health services: a systematic review. Eur J Public Health 2018;28:74-81.

17 Simac L, Ledrans M, Catelinois O. COVID-19 in the vulnerable population of the Saint-Jacques and Haut-Vernet districts of Perpignan (France): Health surveillance carried out using local data [in French]. Bull Epidémiol Hebd 2020;30:590-8.

18 Salmon CT, Nichols JS. The Next-Birthday method of Respondent selection. Public Opinion Quarterly 1983;47:270-6.

19 Haut Conseil de la santé publique. Avis du 29 octobre 2020 relatif l'actualisation de la liste des facteurs de risque de forme grave de Covid-19 [in French. 34. Paris, 2020.

20 Muench P, Jochum S, Wenderoth V, et al. Development and validation of the Elecsys Anti-SARS-CoV-2 immunoassay as a highly 
specific tool for determining past exposure to SARS-CoV-2. J Clin Microbiol 2020;58:e01694-20.

21 Warszawski J, Bajos N, Meyer L. In May 2020, 4.5\% of the population of metropolitan France had developed antibodies against SARS-CoV-2 - The first results of the EpiCov national survey. Études et résultats: Drees, 2020: 6.

22 Pollán M, Pérez-Gómez B, Pastor-Barriuso R, et al. Prevalence of SARS-CoV-2 in Spain (ENE-COVID): a nationwide, population-based seroepidemiological study. Lancet 2020;396:535-44

23 Buitrago-Garcia D, Egli-Gany D, Counotte MJ, et al. Occurrence and transmission potential of asymptomatic and presymptomatic SARSCoV-2 infections: a living systematic review and meta-analysis. PLoS Med 2020;17:e1003346.

24 Byambasuren O, Cardona M, Bell K. Estimating the extent of asymptomatic COVID-19 and its potential for community transmission: systematic review and meta-analysis. medRxiv 2020

25 Makaronidis J, Mok J, Balogun N, et al. Seroprevalence of SARS CoV-2 antibodies in people with an acute loss in their sense of smell and/or taste in a community-based population in London, UK: an observational cohort study. PLoS Med 2020;17:e1003358.

26 Srocynski M, Yeghicheyan J. Les Gitans de Perpignan face la Covid-19. Approche qualitative d'un cluster [in French]: CREAl-ORS Occitanie, 2021: 123.

27 Stringhini S, Wisniak A, Piumatti G, et al. Seroprevalence of antiSARS-CoV-2 IgG antibodies in Geneva, Switzerland (SEROCoVPOP): a population-based study. Lancet 2020;396:313-9.

28 Popkin BM, Du S, Green WD, et al. Individuals with obesity and COVID-19: a global perspective on the epidemiology and biological relationships. Obes Rev 2020;21:e13128.

29 Vernay M, Malon A, Oleko A, et al. Association of socioeconomic status with overall overweight and central obesity in men and women: the French nutrition and health survey 2006. BMC Public Health 2009;9:215.
30 Alberca RW, Oliveira LdeM, Branco ACCC, et al. Obesity as a risk factor for COVID-19: an overview. Crit Rev Food Sci Nutr 2021;61:1-15.

31 Goossens GH, Dicker D, Farpour-Lambert NJ, et al. Obesity and COVID-19: a perspective from the European association for the study of obesity on immunological perturbations, therapeutic challenges and opportunities in obesity. Obes Facts 2020;13:439-52.

32 Deschasaux-Tanguy M, Bourhis L, de Lamballerie X, et al. Body weight, body composition and the risk of SARS-CoV-2 infection in a large population-based sample. J Intern Med 2021. doi:10.1111/ joim.13364. [Epub ahead of print: 08 Jul 2021].

33 Luzi L, Radaelli MG. Influenza and obesity: its odd relationship and the lessons for COVID-19 pandemic. Acta Diabetol 2020;57:759-64.

34 Roederer T, Mollo B, Vincent C, et al. Seroprevalence and risk factors of exposure to COVID-19 in homeless people in Paris, France: a cross-sectional study. Lancet Public Health 2021;6:e202-9.

35 Insee. Logement en 2017 : Recensement de la population - Base infracommunale (IRIS) [in French]. Insee, 2020.

36 Ministry of the City, Youth and Sports. Arrêté du 29 avril 2015 relatif la liste des quartiers prioritaires de la politique de la ville présentant les dysfonctionnements urbains les plus importants et visés en priorité par le nouveau programme national de renouvellement urbain [in French]: JORF $n^{\circ} 0106$ [NOR: VJSV1508731A], 2015. Available: https://www.legifrance.gouv.fr/loda/id/LEGITEXT000030556555/ 2020-08-28/ [Accessed 20 Jan 2021].

37 Burström B, Tao W. Social determinants of health and inequalities in COVID-19. Eur J Public Health 2020;30:617-8.

38 Jackson C, Bedford H, Cheater FM, et al. Needles, Jabs and Jags: a qualitative exploration of barriers and facilitators to child and adult immunisation uptake among gypsies, travellers and Roma. BMC Public Health 2017;17:254.

39 Fernández-Feito A, Pesquera-Cabezas R, González-Cobo C, et al. What do we know about the health of Spanish Roma people and what has been done to improve it? A scoping review. Ethn Health 2019;24:224-43. 